
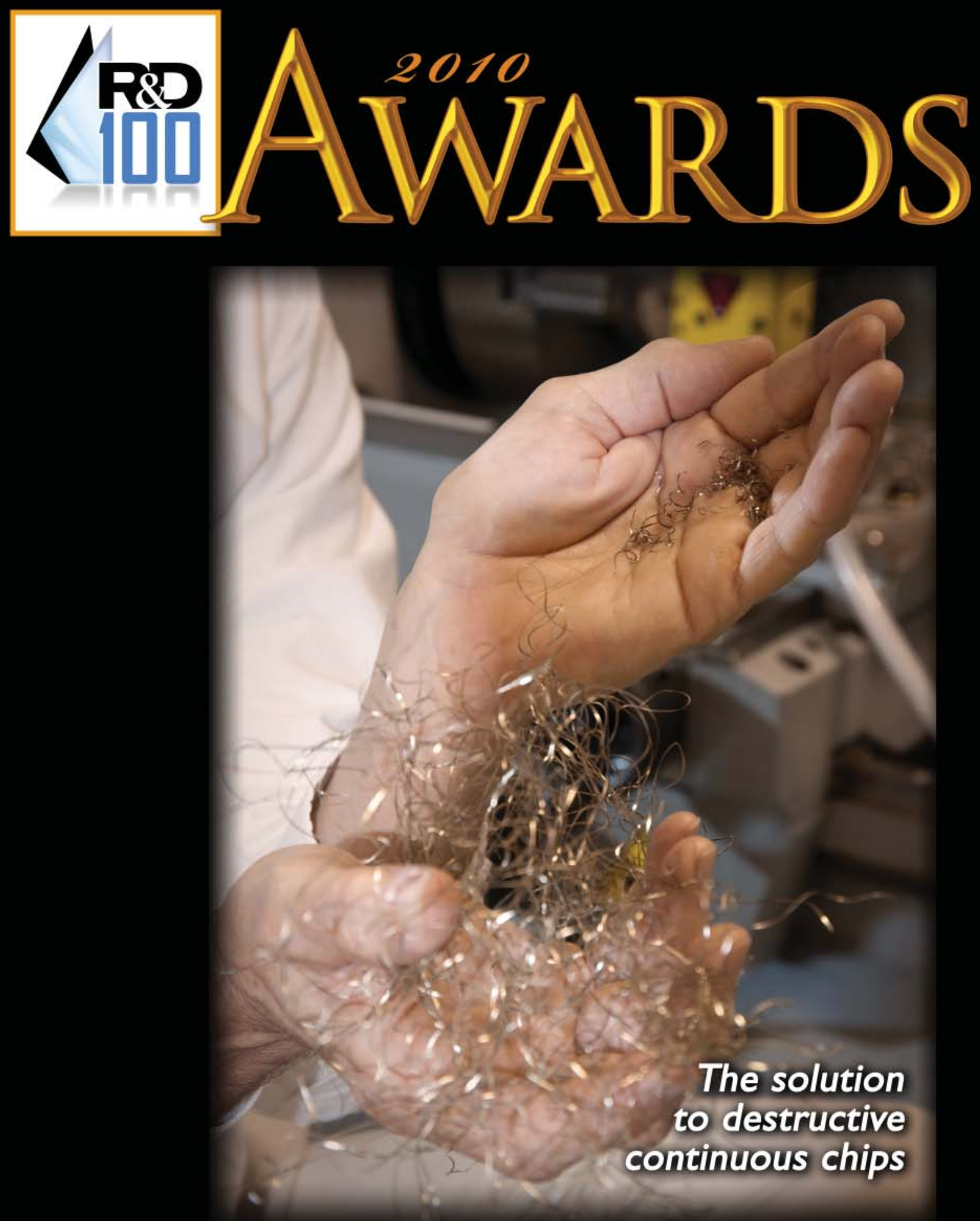

\title{
MODULATED TOOL-PATH (MTP) CHIP BREAKING SYSTEM
}




\section{DISCLAIMER}

This work of authorship and those incorporated herein were prepared by Contractor as accounts of work sponsored by an agency of the United States Government. Neither the United States Government nor any agency thereof, nor Contractor, nor any of their employees, makes any warranty, express or implied, or assumes any legal liability or responsibility for the accuracy, completeness, use made, or usefulness of any information, apparatus, product, or process disclosed, or represents that its use would not infringe privately owned rights. Reference herein to any specific commercial product, process, or service by trade name, trademark, manufacturer, or otherwise, does not necessarily constitute or imply its endorsement, recommendation, or favoring by the United States Government or any agency or Contractor thereof. The views and opinions of authors expressed herein do not necessarily state or reflect those of the United States Government or any agency or Contractor thereof. 


\section{Y-I2 NATIONAL SECURITY COMPLEX}

\section{Modulated Tool-Path (MTP) \\ Chip Breaking System}

\section{R\&D 100 Awards}

April 2010

Prepared by

Y-12 National Security Complex

P.O. Box 2009

Oak Ridge, Tennessee 37831-8169

Managed by

Babcock \& Wilcox Technical Services Y- I2, LLC

for the

U.S. Department of Energy

under contract DE-AC05-00OR22800 


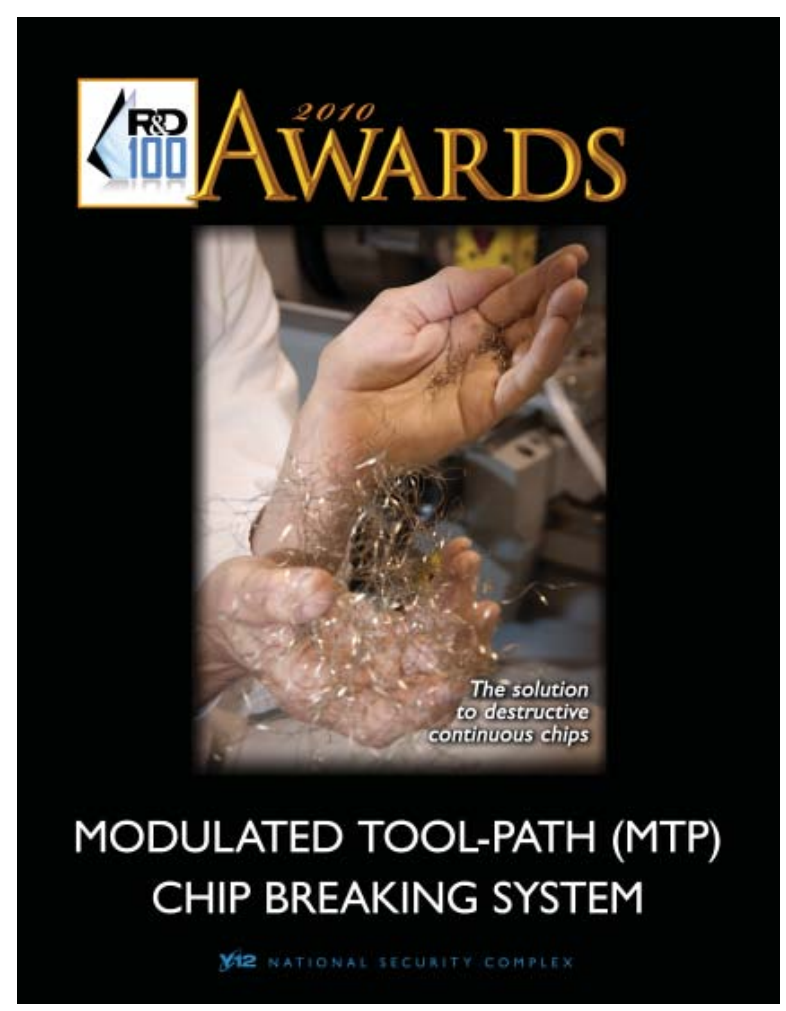

\section{TABLE OF CONTENTS}

1. Submitting Information 1

2. Product Name 3

3. Description 3

4. When Available 3

5. Inventor/Primary Developer 4

6. Product Price 9

7. Patent/Patent Pending 9

8. Product Primary Function 10

9. Product Primary Competition 17

10. Product Application 19

11 Summary 20

12. Affirmation 21

Appendix A: Media Coverage $\quad 22$ 


\section{SUBMITTING INFORMATION}

\section{A. SUBMITTING ORGANIZATION}

\section{Organization Name}

Y-12 National Security Complex

\section{Submitter's Name}

Tammy Graham

Director of Technology Transfer

Office of Technology Transfer

\section{Address}

Y-12 National Security Complex

P.O. Box 2009, MS 8091

\section{City/State}

Oak Ridge, TN

\section{Zip/Postal Code}

37831-8091

\section{Country}

USA

Phone

(865) 574-2214

\section{Fax}

(865) 241-4614

\section{Email}

grahamtb@y12.doe.gov 


\section{B. CONTACT PERSON}

Name

Gina Davis

Director of Marketing and Commercialization

Organization Name

Office of Technology Transfer

Address

Y-12 National Security Complex

P.O. Box 2009, MS 8112

\section{City/State}

Oak Ridge, TN

\section{Zip/Postal Code}

37831-8112

\section{Country}

USA

Phone

(865) 576-0181

Fax

(865) 241-3892

Email

davisgk@y12.doe.gov

\section{C. JOINT ENTRY}

Not applicable 


\section{PRODUCT NAME}

MODULATED TOOL-PATH (MTP) CHIP BREAKING SYSTEM

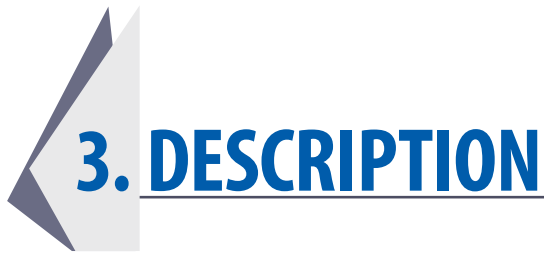

The Modulated Tool-Path (MTP) Chip Breaking System produces user-selectable chip lengths and workpiece finishes and is compatible with any material, workpiece shape, and depth of cut.

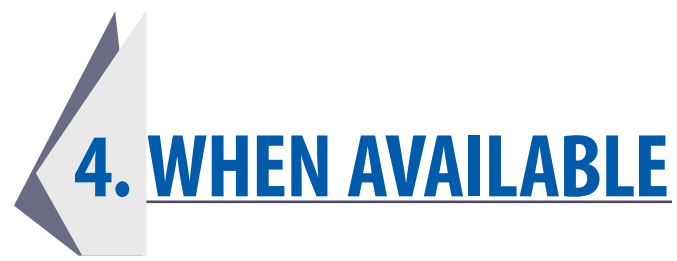

The product first became available in December 2009.

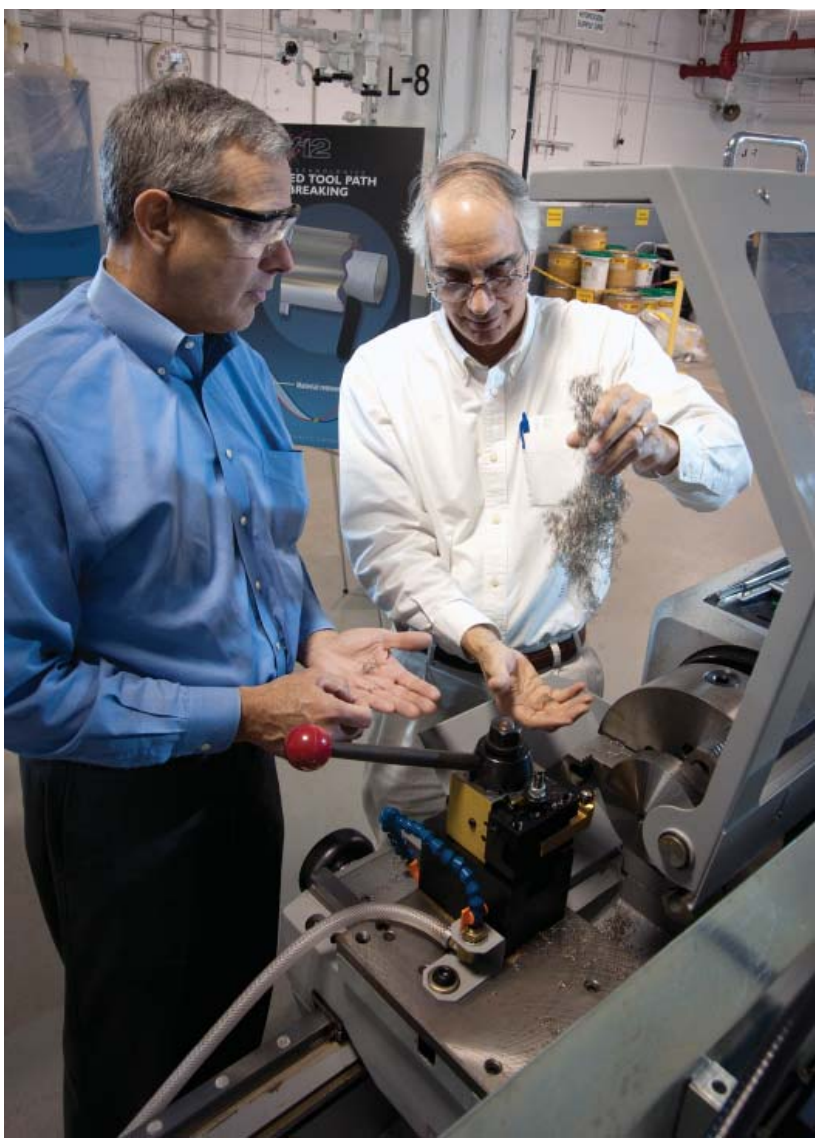

The small chip fragments the system produces help prevent equipment damage, delivery delays, and injury.

"Research sponsored by the U.S. Department of Energy and performed at Y-12 National Security Complex, managed by Babcock \&Wilcox Technical Services Y-12, LLC, for the U.S. Department of Energy under contract DE-AC05-000R22800. The submitted manuscript has been authored by a contractor of the U.S. government under contract No. DE-AC05-00OR22800. Accordingly, the U.S. government retains a nonexclusive, royalty-free license to publish or reproduce the published form of this contribution, or allow others to do so, for U.S. government purposes. 


\section{INVENTOR/PRINCIPAL DEVELOPER}

Principal Developer

William E. Barkman

\section{Position}

Program Manager

\section{Organization}

Science, Technology \& Partnerships

\section{Address}

Y-12 National Security Complex

P.O. Box 2009, MS 8097

Oak Ridge, TN 37831-8097

\section{Phone}

(865) 574-1843

\section{FAX}

(865) 574-1809

\section{E-Mail}

barkmanwe@y12.doe.gov

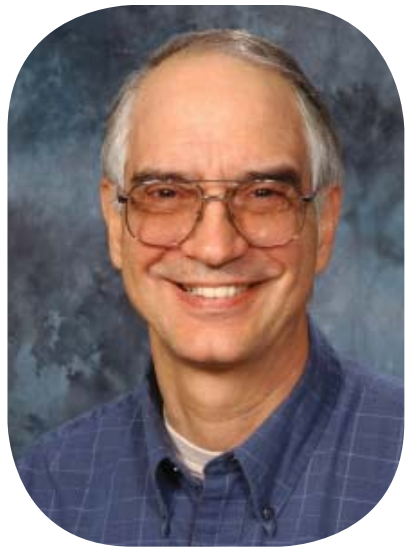

William E. (Bill) Barkman has an extensive background in precision manufacturing operations. At Y-12 he develops machining and inspection systems that are capable of automated operations in rigorous manufacturing environments. He has wide experience in the development and execution of collaborative partnership activities for the National Nuclear Security Administration, including the areas of agile machining and inspection, digital radiography, noncontact inspection, university projects, and ceramics machining.

Barkman was the first chairman of the Network of Senior Scientists and Engineers. He has worked as a program manager in the precision manufacturing area, and he has served as a precision manufacturing consultant to Los Alamos National Laboratory. He has authored more than 45 technical publications, including the book Inprocess Quality Control for Manufacturing, and developed a manufacturing-variability course.

He holds a B.E. and an M.S. in mechanical engineering from Vanderbilt University and an M.S. in electrical engineering from Tulane University. 


\section{B. ADDITIONAL INVENTORS/DEVELOPERS}

Name (2)

Edwin F. Babelay, Jr.

Position

Engineer

Organization

Science, Technology and Partnerships

Address

Y-12 National Security Complex

P.O. Box 2009, MS 8084

Oak Ridge, TN 37831-8084

Phone

(865) 574-1873

FAX

(865) 576-2782

E-Mail

babelayefjr@y12.doe.gov
Name (3)

K. Scott Smith

Position

Chairman, Department of Mechanical Engineering

Organization

University of North Carolina at Charlotte

Address

9201 University City Blvd.

Duke Centennial Hall, Rm. 108A

Charlotte, NC 28223-0001

\section{Phone}

(704) 687-8350

\section{FAX}

(704) 687-8345

\section{E-Mail}

kssmith@uncc.edu 


\section{B. ADDITIONAL INVENTORS/DEVELOPERS}

$\begin{array}{ll}\text { Name (4) } & \text { Name (5) } \\ \text { Bethany A. Woody } & \text { David Adams } \\ \begin{array}{l}\text { Position } \\ \text { President }\end{array} & \begin{array}{l}\text { Position } \\ \text { Engineer }\end{array} \\ \text { Organization } & \text { Organization } \\ \text { InSituTec } & \text { Moore Nanotech } \\ \text { Address } & \text { Address } \\ 45 \text { Odell School Road, Suite A } & \text { 230 Old Homestead Hwy. } \\ \text { Concord, NC 28027 } & \text { Swanzey, NH 03446 } \\ \text { Phone } & \text { Phone } \\ \text { (704) 782-0593 } & (603) 352-3030 \\ \text { FAX } & \text { FAX } \\ \text { (704) 782-0597 } & (603) 352-3363 \\ \text { E-Mail } & \\ \text { bethany.woody@insitutec.com } & \end{array}$




\section{B. ADDITIONAL INVENTORS/DEVELOPERS}

\author{
Name (6) \\ David Tursky \\ Position \\ Graduate Student \\ Organization \\ University of North Carolina at Charlotte \\ Address \\ 9201 University City Blvd. \\ Duke Centennial Hall \\ Charlotte, NC 28223-0001 \\ Phone \\ (704) 421-8757
}

\section{FAX}

(704) 687-8345

\section{E-Mail}

datursky@unce.edu

\section{Name (7)}

Thomas Assaid

\section{Position}

Graduate Student

Organization

University of North Carolina at Charlotte

Address

9201 University City Blvd.

Duke Centennial Hall

Charlotte, NC 28223-0001

\section{Phone}

(919) 801-8655

FAX

(704) 687-8345

\section{E-Mail}

tsassaid@uncc.edu 


\section{B. ADDITIONAL INVENTORS/DEVELOPERS}

Name (8)

Justin McFarland

\section{Position}

Graduate Student

\section{Organization}

University of North Carolina at Charlotte

\section{Address}

9201 University City Blvd.

Duke Centennial Hall

Charlotte, NC 28223-0001

\section{Phone}

(919) 801-8655

\section{FAX}

(704) 687-8345 


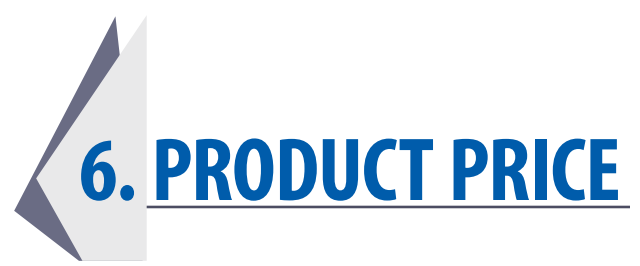

To potential users having existing computer numerical control (CNC) machining operations, the cost to deploy the chip cutting modulation will be the procurement of the software sublicense from a licensed commercial vendor, along with individualized training and integration analysis tools.

\section{PATENT/PATENT PENDING}

U.S. Patent Application 12/251,247, "Methods and Systems for Chip Breaking in Turning Applications Using CNC Toolpaths," filing date 10/14/2008, UNC Charlotte and B\&W Y-12.

U. S. Patent Application 12/760,115, "Method and Apparatus for Characterizing the Dynamic Performance of Machine Tools," filing date 04/14/2010, B\&W Y-12.

U.S. Patent Application 12/760,159, "Method and Apparatus for Characterizing and Enhancing the Functional Performance of Machine Tools," filing date 04/14/2010, B\&W Y-12 and UNC Charlotte. 


\section{PRODUCT PRIMARY FUNCTION}

\section{The Problems with Conventional Machining Operations}

Conventional machining operations that involve the turning or boring of ductile materials create a continuous or semi-continuous chip, as Fig. 1 shows; and that chip frequently becomes entangled in a so-called bird nest (Fig. 2a-b).

This bird nest can damage the workpiece or the machine tool, poses a significant safety hazard to the machine operator, and complicates the postmachining cleanup operations. Although many chip breaking technologies have been marketed, and they perform well in some situations, they often must be "fine tuned" whenever a new application is encountered.
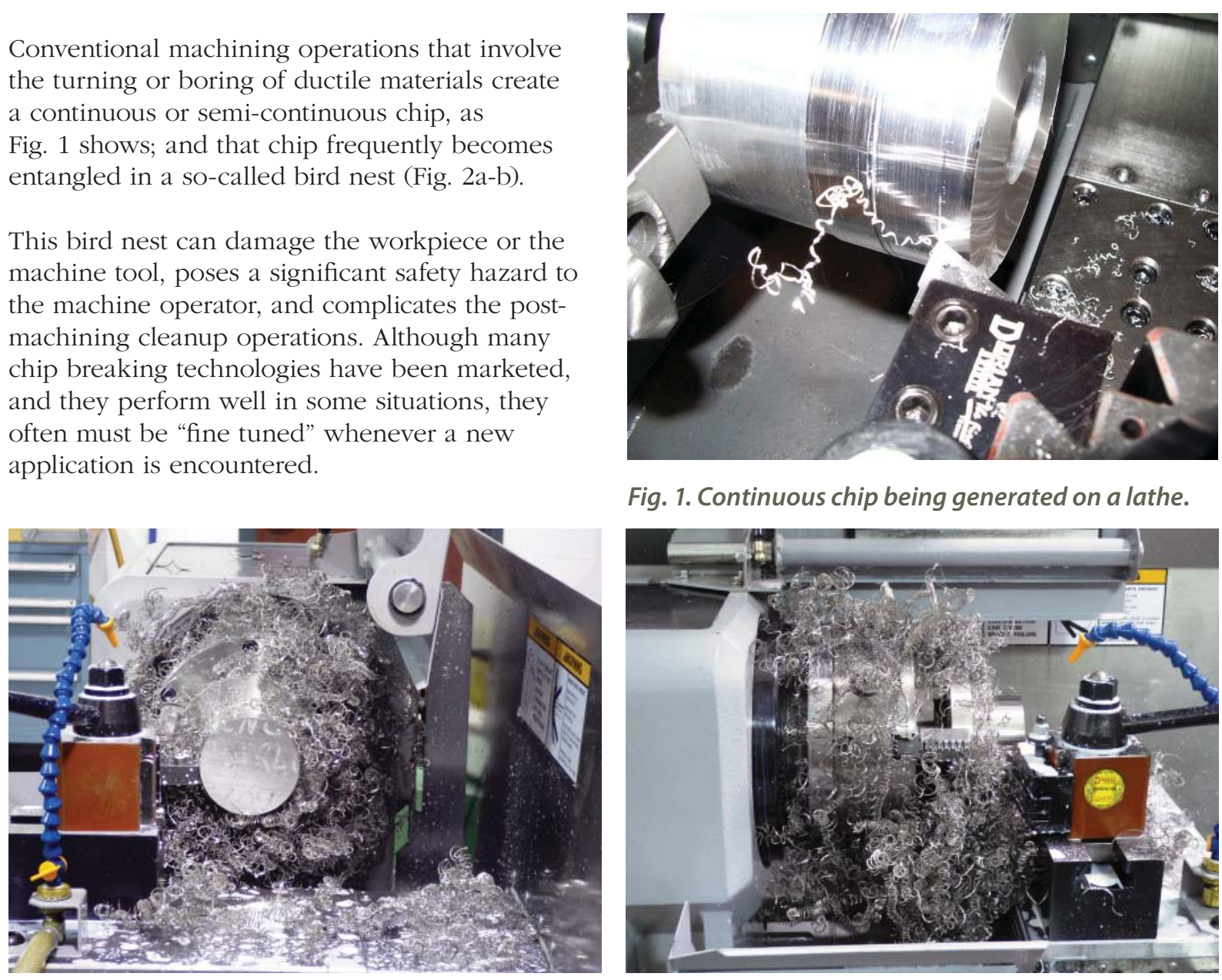

Fig. 1. Continuous chip being generated on a lathe.

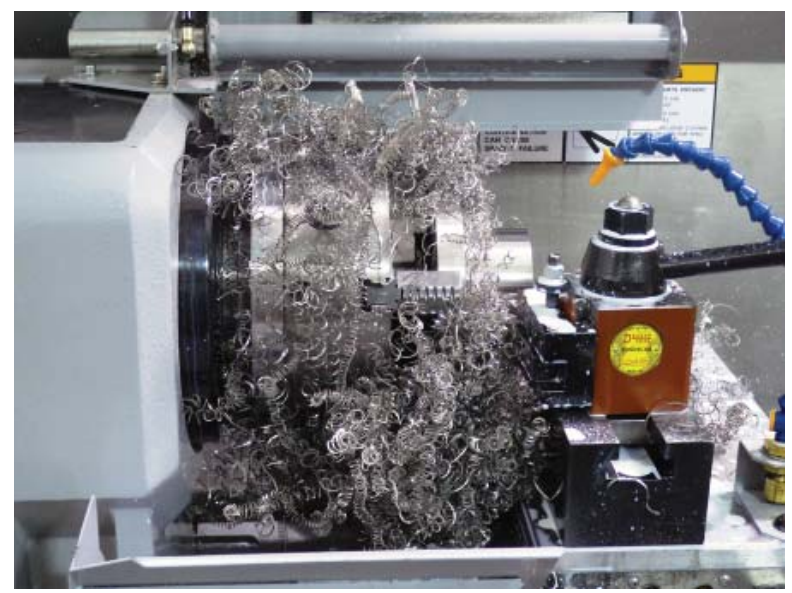

Fig. 2a-b. Bird nest caused by continuous, entangled chips. 
In addition, none of those systems provides a solution for all materials, all workpieces, and all machining depths of cut.

\section{The MTP Chip Breaking System's Solutions}

The Modulated Tool-Path (MTP) Chip Breaking System uses computer modeling and simulation techniques to automatically produce a chip breaking motion that avoids the shortcomings of existing systems. Among its many virtues, the MTP chip breaking system enables users to create predetermined chip lengths while machining any workpiece material in any shape and with any depth of cut. No competing chip breaking approach covers the wide range of applications available with the MTP chip breaking system, and no other technique provides as wide a range of user-selectable chip lengths.

The MTP chip breaking system consistently creates the desired size of broken chipswhatever the workpiece size, shape, or material — and the machine operator does not have to make any adjustments during the machining operation. The MTP system's programmer configures the part program that, in turn, guides the machine tool to deliver the desired part size, shape, chip length, and workpiece surface finish. The MTP system helps manufacturers avoid the detrimental effects of continuous chips, such as expensive machine-repair costs, product-delivery delays, and workplace injuries.

The MTP chip breaking system also benefits turning and boring operations that have to tailor a workpiece surface texture to fall within a specific range or that have to reduce the temperature of a cutting tool during a machining pass.

The user first determines the existing machine tool's capabilities and then selects the chip breaking parameters, the operational "sweet spot," in order to

\section{Play video file (right) for a more detailed explanation of the MTP chip breaking system.} attain the desired result.

The production factors taken into account can be conflicting: What is the desired chip length? How tight are the tolerances for this particular operation? What is the output demand?

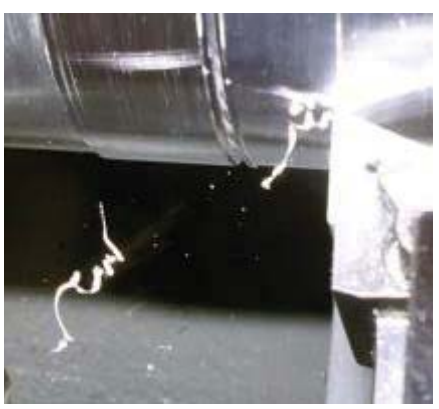

Fig. 3. The MTP chip breaking system creates segmented chips. Click on image above to play. 
If only a rough cut is needed-cutting ends off pipes, for instance-a high-speed parameter set can be appropriate because the throughput can be achieved within the allowed product quality requirements.

When tight-tolerance parts are essential, the user selects chip breaking parameters that ensure that the needed product quality is delivered.

In Fig. 4a (top) and 4b, Bill Barkman (right) shows a visitor the small segmented fragments that the MTP chip breaking system produces.

The MTP system generates a cutting-tool motion that oscillates, along the tool-path vector, so that the cutting tool periodically engages and disengages from the cut face and, thereby, creates a broken or segmented chip, as Fig. 3 shows.

The most important process parameters associated with the MTP chip breaking system are the phase between spindle rotation and the axes oscillation, the ratio of the oscillation amplitude to the global feed rate of the cutting tool, and the ability of an individual machine to execute specific oscillation commands. Other important process parameters include the desired length of the chips and the quality of the workpiece surface finish.

Figure 5 shows an exaggerated view of the cut face on a cylindrical workpiece as a means of describing the MTP chip breaking process. (The same effect occurs at any machining tool-path vector, but the resulting graphic can be more difficult to draw.) As the machine spindle rotates the workpiece in Fig. 5, the cutting tool executes a "two steps forward, one step back" type of motion that creates waves in the cut face of the workpiece as the tool advances in the Z-axis direction (Fig. 6).
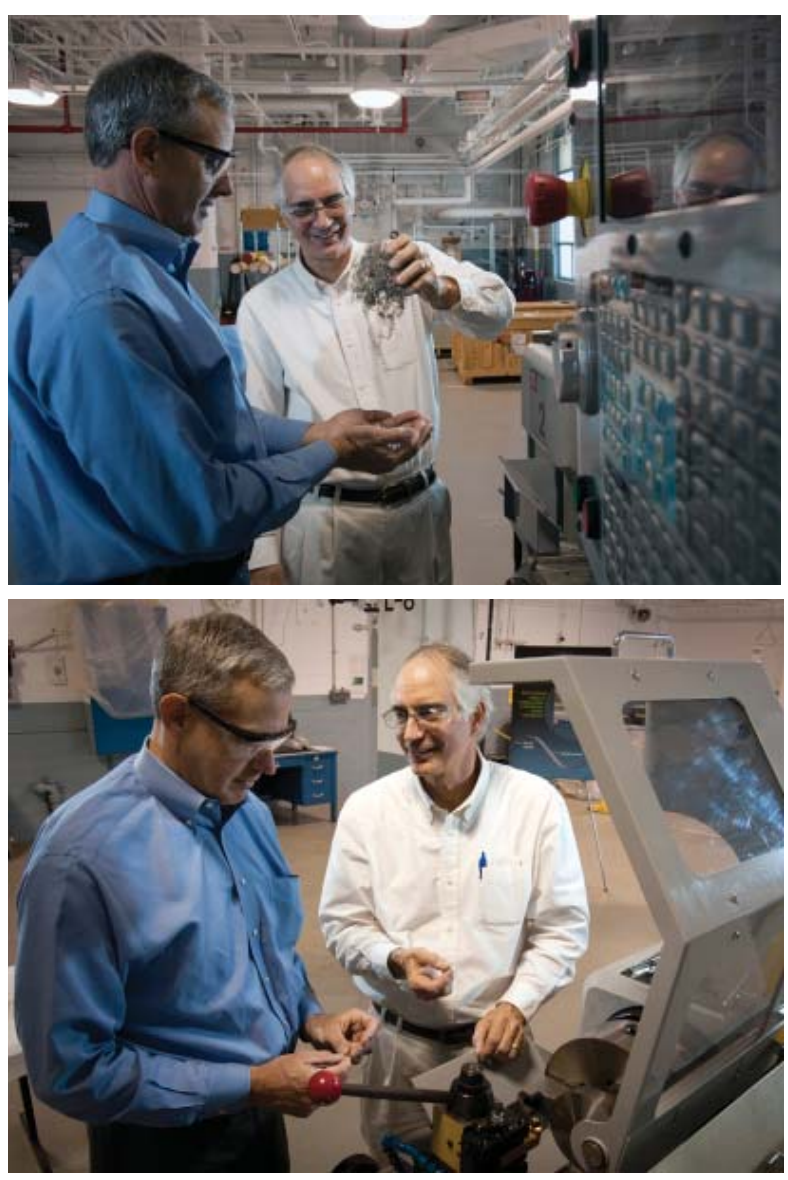

Fig. 4a-b. Users obtain any chip length for any material in any shape and with any depth of cut. Operators do not have to adjust the machine as it runs. 
In order for the MTP chip breaking to occur, there must be a sufficient amount of oscillation amplitude and phase shift from one workpiece rotation to the next to periodically disengage the tool from the cut face. Figure 7 displays this interrupted cutting action and shows how the current tool path interacts with the cut face profile created on previous part rotations to create variations in the chip thickness. As the chip thickness approaches zero, the chip breaks and produces a chip length that relates to the part circumference. (Multiple engagements and disengagements in a single spindle revolution create chips that are shorter than the part circumference; multiple rotations per engagement and disengagement produce longer chips.)

Fig. 5 (left) Exaggerated view of the workpiece cut face that the system produces.

Fig. 6 (right). Chip breaking tool path for machining a cylindrical workpiece.

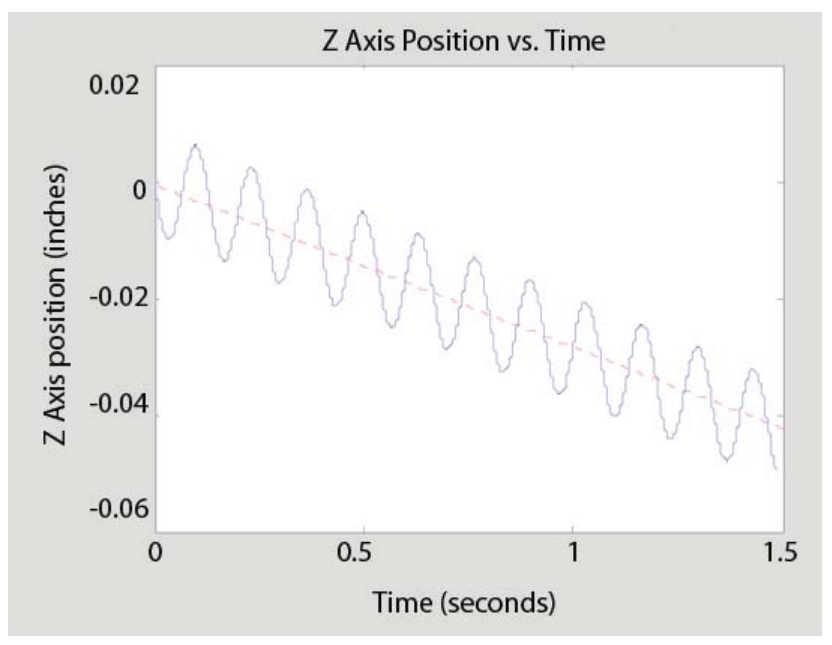

Fig. 7. Graphic showing how the interaction of the current tool position with the previously cut surface produces $a$ segmented chip.

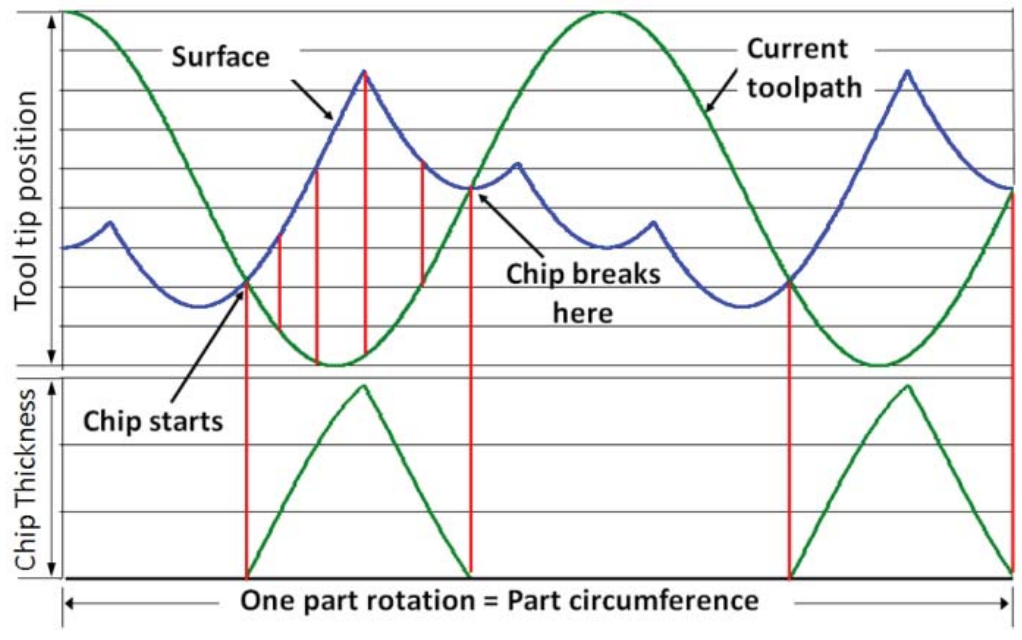


Figure 8 shows a model of the "chip breaking regime" in terms of the phase shift between the oscillation motion and the spindle rotation (from one spindle rotation to the next) and the ratio of the oscillation amplitude divided by the global axis feed per revolution, RAf. (The global feed rate is the average velocity of the cutter along the tool path and is often expressed in terms of distance traveled per revolution of the spindle. The instantaneous axis feed rate is the sum of the global axis feed rate and the oscillation feed rate that is in effect at a particular point on the tool path.) It should be noted that RAf values higher than about 3 do not significantly impact a machine's ability to break chips. (The lower RAf values also reduce the dynamic performance requirements for the machine tool.) Also, the use of MTP chip breaking process parameters that produce a phase shift close to $180^{\circ}$ minimizes the value of RAf needed to produce segmented chips.

Figure 9 provides another model view of the MTP chip breaking process in terms of the interaction between the oscillation rate (oscillation waves per spindle revolution) and the chip length when RAf is equal to one. As shown earlier, small amounts of phase shift do not produce the needed interrupted cut. In addition, relatively small reductions in chip length are achieved with waves-per-revolution values beyond 2.5. Figure 10 includes the RAf axis, thereby adding a third dimension to the information provided in Fig. 9.

Another important consideration in the choice of MTP parameters is the workpiece

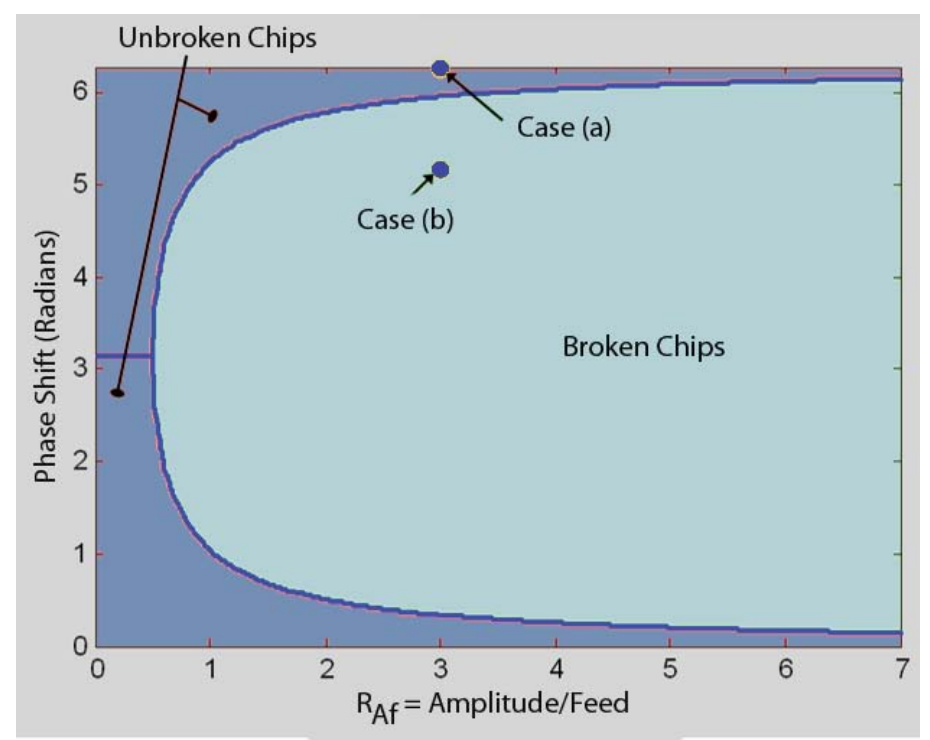

Fig. 8. Model of the broken and unbroken chip zones in relation to the phase between the spindle rotation and the oscillation motion, and the oscillation amplitude divided by global axis feed per spindle revolution.

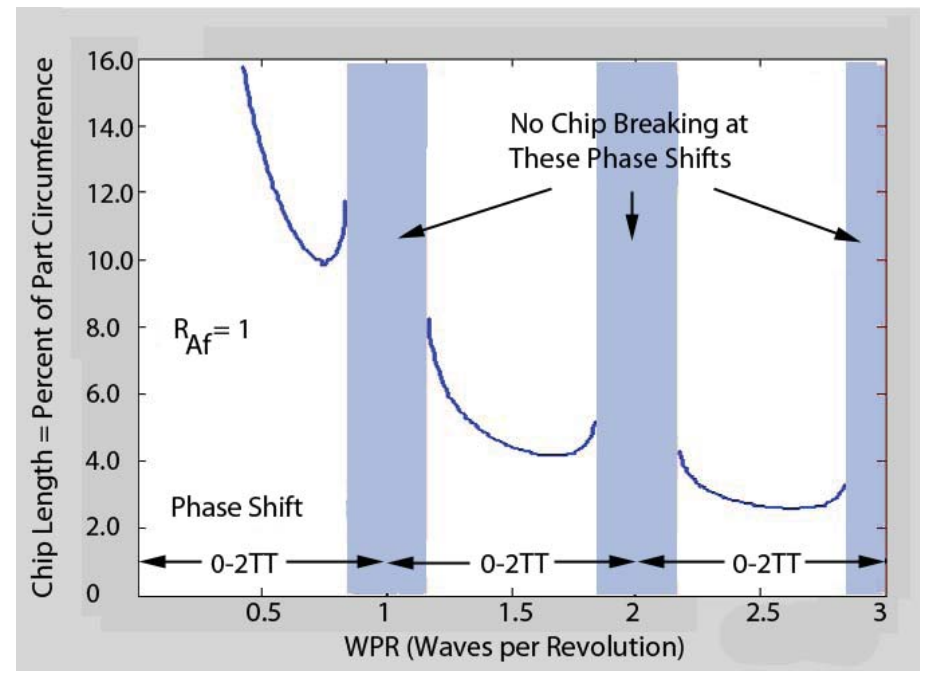

Fig. 9. Relationship between oscillation rate and chip length. 
surface finish. Because the axis oscillation requires the tool to travel a longer distance than would be required with a nonMTP tool path, the instantaneous feed rate has to be significantly higher than the global feed rate in order to achieve the same machining time for a given workpiece. This increase in feed rate impacts the part surface finish and can create a conflict between machining time and chip control goals. Alternatively, the global feed rate can often be reduced because nonproductive time spent clearing the bird nests from the machine is eliminated. In either case, it is important to understand the relationship between the MTP process parameters and the workpiece surface finish so that the throughput and quality parameters can be optimized.

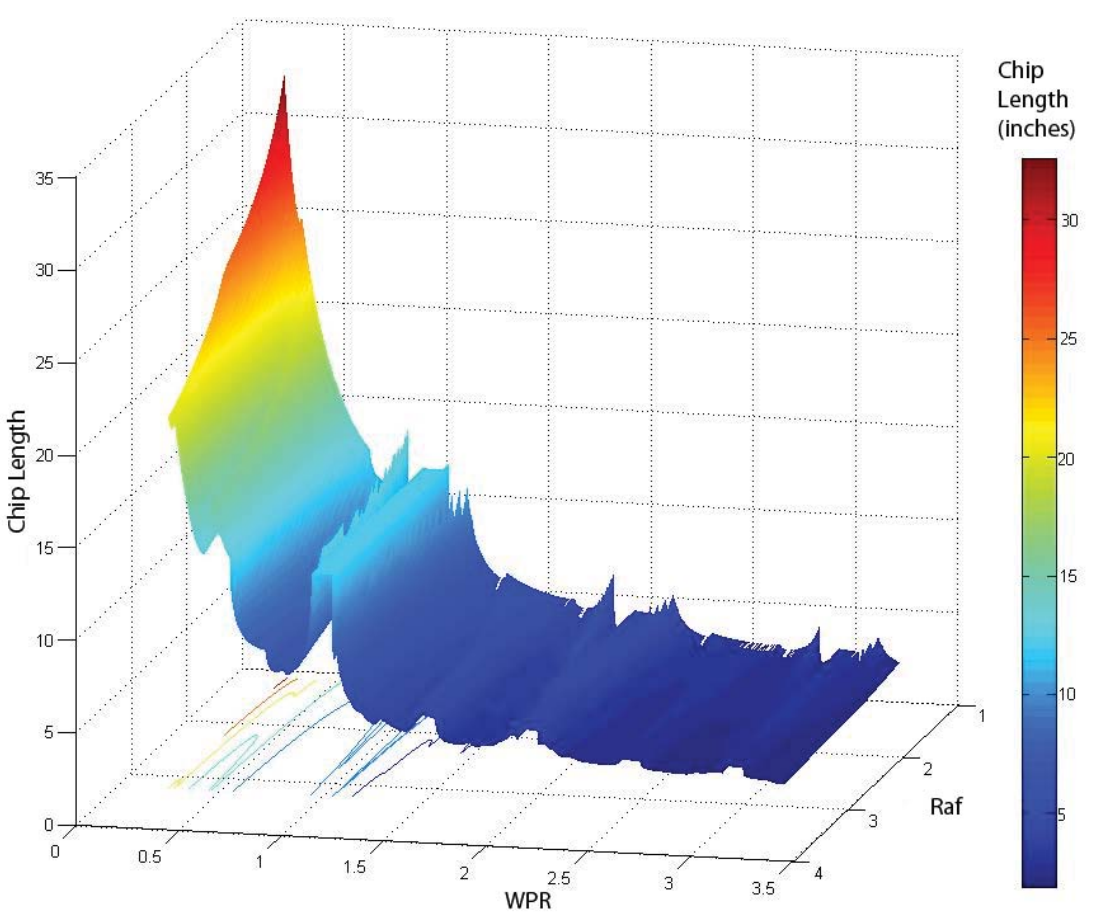

Fig. 10. Relationship between chip length, oscillation rate, and $R_{A f^{*}}$

Figures 11 and 12 show two views

of a theoretical surface finish model that can guide a user in selecting the part program parameters that should be used in a particular MTP chip breaking application. It should be noted that the surface in Fig. 11 is symmetric around integer multiples of 0.5 oscillations per revolution. This allows the user a significant degree of flexibility in selecting MTP parameters that will produce a particular combination of surface finish and chip length target values.

Another critical aspect of the MTP chip breaking system is that a given machine tool must be able to execute the oscillatory tool-path commands that are generated in response to the MTP parameter selection. The MTP chip breaking system provides methods for characterizing a machine tool's ability to execute the oscillatory motions involved in the MTP process and allows the user to select the operational "sweet spot" that combines the often conflicting goals of chip length, workpiece quality, and throughput with the dynamic motion capabilities of a specific machine tool. 
Fig. 11. MTP chip breaking surface finish model. Topographical plot of Ra values corresponding to a 0.003 ipr feedrate, 0.031-in. tool, and a range of oscillations per revolution and oscillation amplitudes.

Fig. 12. Overhead view of symmetrical region of surface finish model.
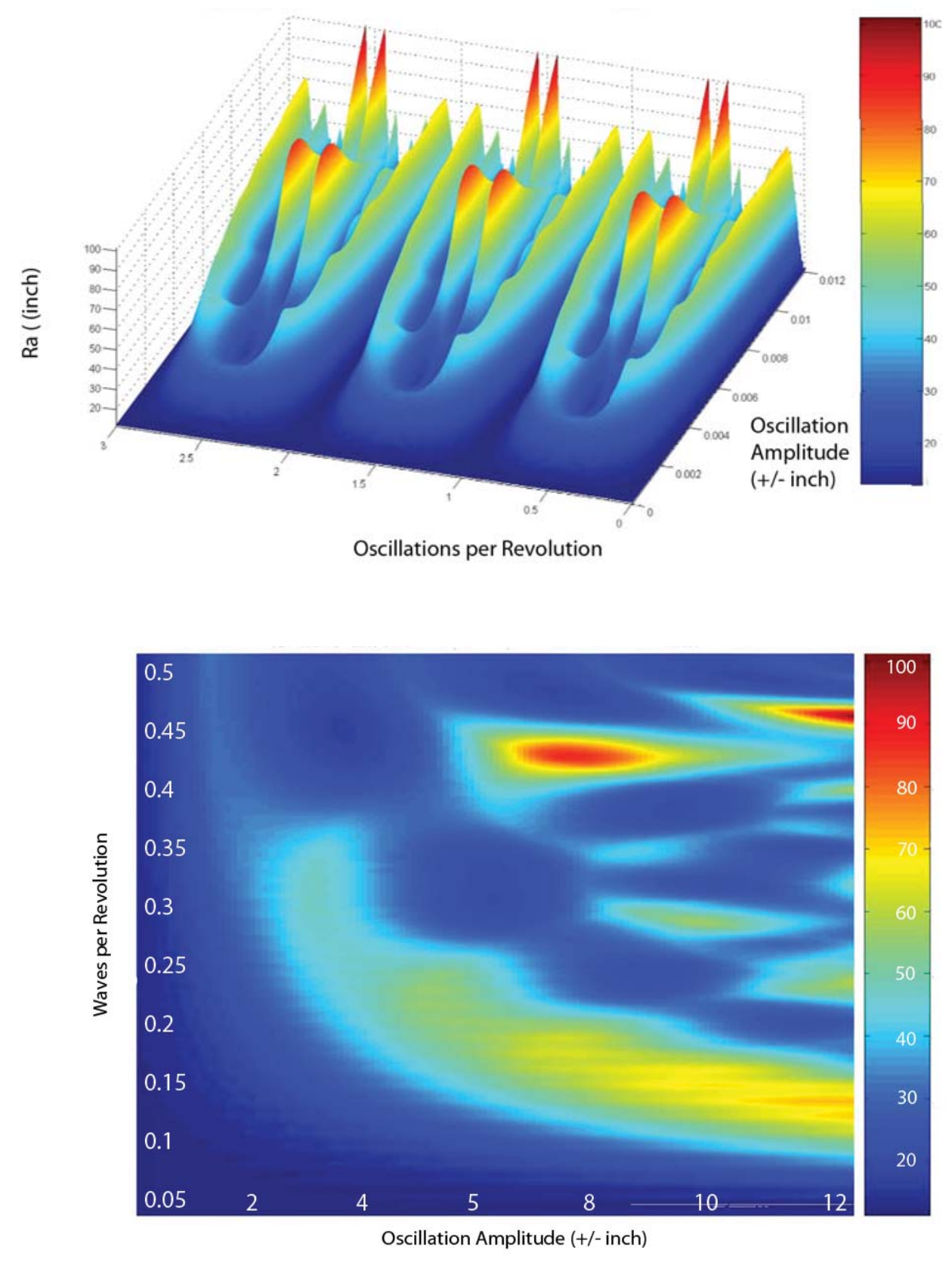


\section{PRODUCT PRIMARY COMPETITORS}

\section{A. PRODUCT'S COMPETITORS}

Competing chip breaking technologies are cutting tools with formed chip breaking profiles, vibratory systems to move the cutter or machine axis in a single direction, and high-pressure jets to bend the chip and break it.

\section{B. KEY FEATURE COMPARISONS}

\begin{tabular}{|c|c|c|c|c|c|}
\hline \multirow{2}{*}{ Key Feature } & \multirow{2}{*}{ MTP System } & \multicolumn{3}{|c|}{ Competition } & \multirow{2}{*}{ MTP System Advantage } \\
\hline & & Formed Tool & Single-Axis Vibration & High-Pressure Jet & \\
\hline Works with all part shapes & YES & Limited & No & Limited & Works with all part shapes \\
\hline $\begin{array}{l}\text { Works with light depths of cut } \\
(0.005 \text { in.) }\end{array}$ & Yes & No & Yes & Limited & Works with all depths of cut \\
\hline Works with all materials & Yes & Limited & Yes & Limited & Works with all materials \\
\hline Special cutting tool required & No & Yes & No & No & Works with all cutting tools \\
\hline Auxiliary equipment required & No & No & Yes & Yes & $\begin{array}{l}\text { No auxiliary equipment } \\
\text { required }\end{array}$ \\
\hline $\begin{array}{l}\text { Compatible with all machine } \\
\text { configurations }\end{array}$ & Yes & Yes & No & No & $\begin{array}{l}\text { No machine configuration } \\
\text { limitations }\end{array}$ \\
\hline Reduces cutting tool temperature & Yes & No & Yes & Yes & $\begin{array}{l}\text { Lower cutting temperatures } \\
\text { extend tool life }\end{array}$ \\
\hline User-selectable chip lengths & Yes & No & No & No & User-selectable chip lengths \\
\hline $\begin{array}{l}\text { Process parameter selection } \\
\text { guide }\end{array}$ & Yes & Limited & No & Limited & $\begin{array}{l}\text { Process parameter selection } \\
\text { guide }\end{array}$ \\
\hline
\end{tabular}




\section{C. IMPROVEMENT UPON COMPETITOR PRODUCTS OR TECHNOLOGIES}

The MTP chip breaking system enables the user to create predetermined chip lengths while machining any workpiece material in any shape and with any depth of cut. Although some of the other chip breaking techniques work well in specific areas, none of the other approaches covers the wide range of applications available with the MTP chip breaking system, and none of the other techniques allows the user to easily select the length of the broken chips. (This is especially important in chip recycling operations.)

The principal application for the MTP chip breaking system is for machining operations that create continuous chips that are hazardous to the workpiece, the machine tool, and the machine operator.
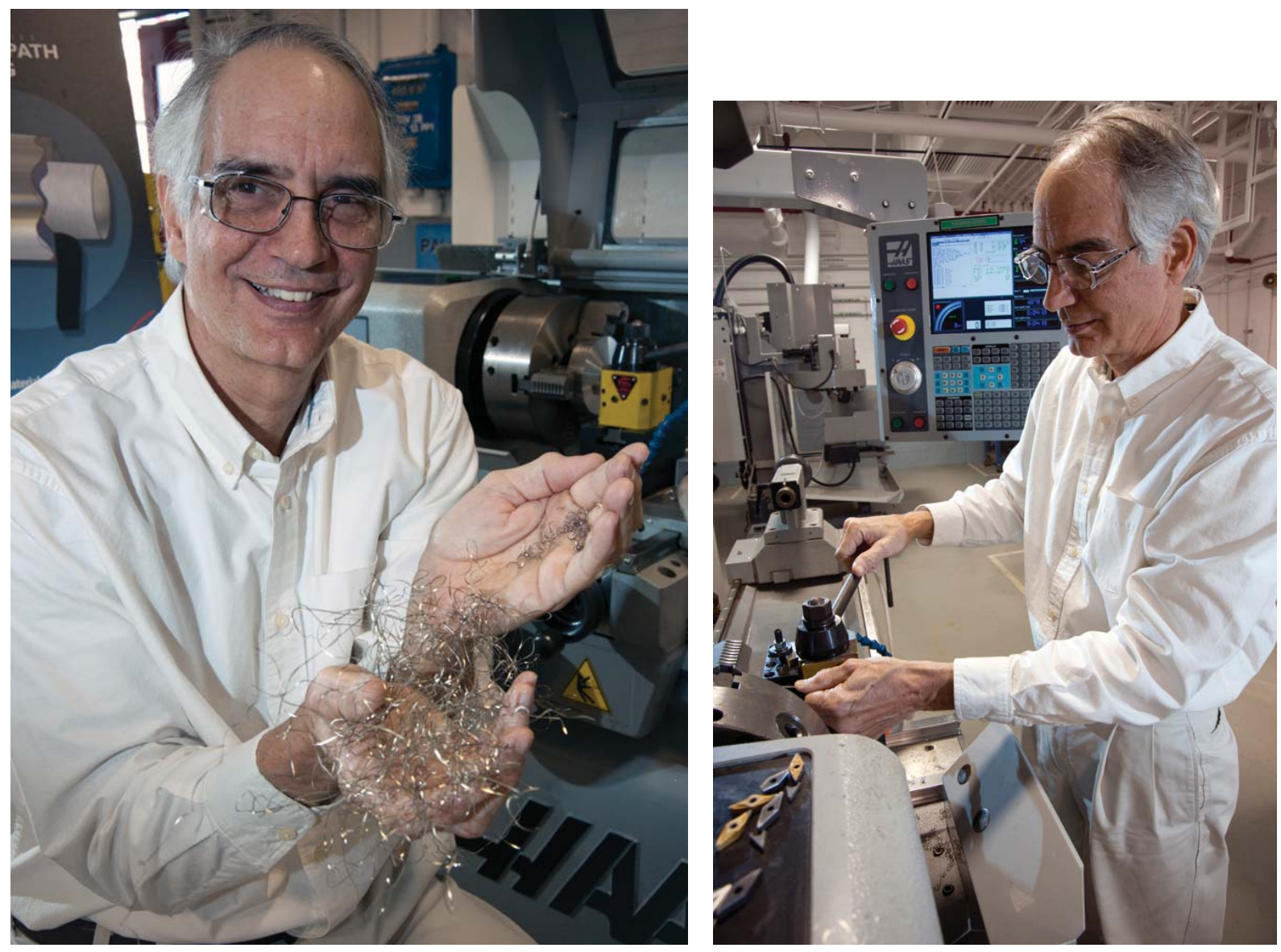

Fig. 13a-b. The contrast between the bird nest effect and the predetermined chip lengths is clearly evident. No other chip breaking system covers the range of applications or allows users to select chip lengths so easily. 


\section{RO. PRODUCT APPLICATION}

\section{A. PRINCIPAL APPLICATION OF PRODUCT}

The MTP chip breaking system provides an unmatched chip breaking solution for machining operations that create continuous chips that can damage the workpiece or machine tool and pose hazards to the machine operator.

\section{B. ADDITIONAL APPLICATIONS}

The MTP chip breaking system also applies to turning and boring operations in which (1) the workpiece surface texture needs to be tailored to fall within a specific range, or (2) the temperature of the cutting tool needs to be reduced during the machining pass. 


\section{SUMMARY}

The MTP chip breaking system consistently creates the desired size of chips regardless of workpiece size, shape, or material, and the machine operator does not need to make any adjustments during the machining operation. The system's programmer configures the part program that commands the machine tool to move in a specific fashion to deliver the desired part size, shape, chip length, and workpiece surface finish. The MTP chip breaking system helps manufacturers avoid the detrimental effects of continuous chips, including expensive repair costs, delivery delays, and hazards to personnel.
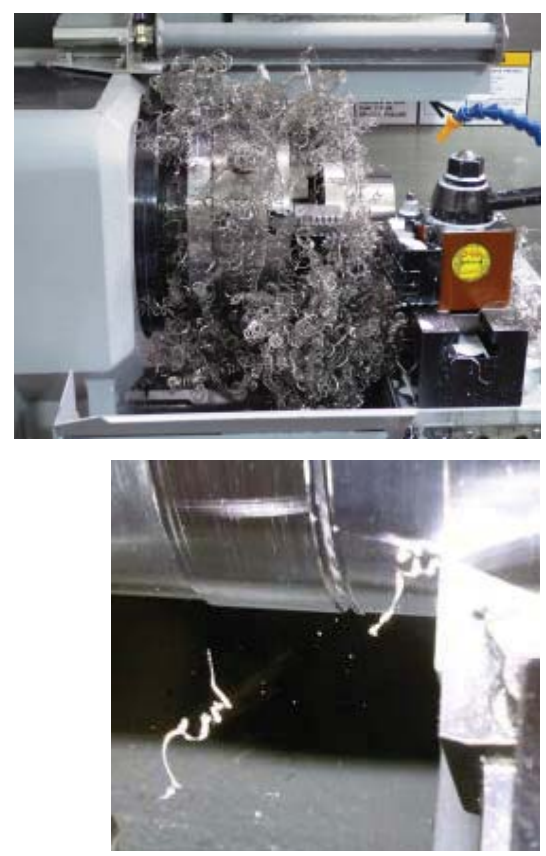

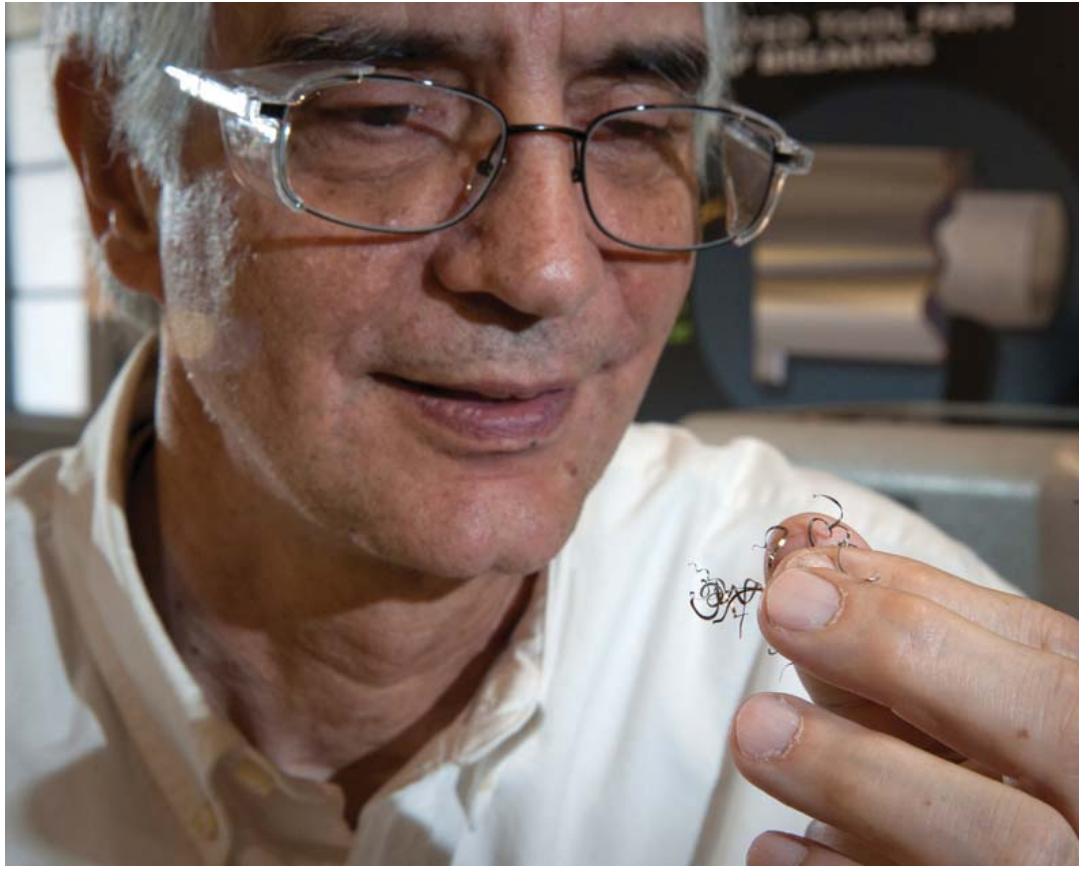

Fig. 14a-c. The MTP chip breaking system avoids the ruinous continuous-chip effect (14a, top left) by producing selectable chip lengths (Fig. 14b, bottom left). The tiny chips ( Fig. 14c, right) enable manufacturers to avoid expensive machine damage and production delays as well as worker injury. 
Modulated Tool-Path (MTP) Chip Breaking System

12. AFFIRMATION

I affirm that all information submitted as part of, or supplemental to, this entry is a fair and accurate representation of this project.

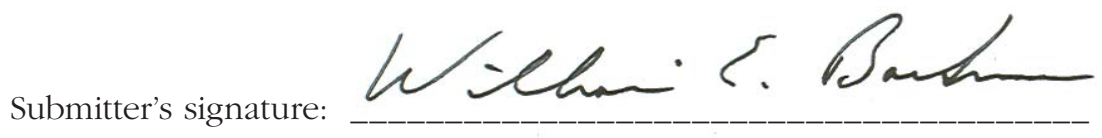

21 


\section{APPENDIX A - MEDIA COVERAGE}




\section{Network sparks answers to shared questions}

Bring experts together and good things will happen-that's the idea behind the Network of Senior Scientists and Engineers, an advisory and working group of technical people from across the NWC. The group's focus is finding and removing barriers to new technology, enabling collaborations and developing and retaining critical skills.

NSSE was chartered by and works closely with the Interplant Technology Team, which includes a technology manager from each NWC site. Kevin Finney, Applied Technologies manager, is Y-12's representative and past IPTT chair. "IPTT acts as the steering group for the senior scientists, and it's a great collaboration between key technology managers from across the weapons complex and the top technical know-how," he said. "IPTT and NSSE also act as advisory groups for National Nuclear Security Administration Headquarters management regarding crosscutting technology issues and development of approaches to managing technology."

John Gertsen, Engineering manager and incoming NSSE chair, pointed to issues the team has taken up. "We've been able to address common concerns and arrive at effective and money-saving improvements," he said. "A number of the changes would not have happened without such broad-based representation."

One question the group tackled was how to ensure unauthorized cell phones are not taken into limited areas. The result is a monitoring system at portals that warns employees if they are carrying a cell phone. Testing of a prototype proved successful at the Savannah River Site, and the technology is expected to be implemented across the Complex.
NSSE is working on replacement of the electronics on aging high-resolution mass spectrometers. To simplify maintenance, the group devised a way of substituting readily available, standardized electronics. Gas analysis techniques that rely on much smaller, less expensive instruments, such as infrared analyzers and ion cyclotron resonance mass spectrometers, are being developed.

\section{"By not reinventing} the wheel at each site, the Complex should benefit significantly."

-Bill Barkman, first NSSE chair

Devising a standard for digital radiography, which is rapidly replacing film radiography, is another target. Because the NWC does not have a standard to interface the two technologies, critical data generated today may be unreadable in a few years. NSSE worked for NNSA's adoption of a common standard (DICONDE used by the medical industry), which will ensure backward compatibility and readability among all sites.

NSSE and IPTT coordinate NNSA's Future Technologies Conference, knowledge preservation seminars and training programs. Members come from each production plant and the production-related areas of national laboratories. Other Y-12 NSSE members are Engineering's Ken Lewis, the Uranium Center of Excellence's Pamela Moor and Louis Powell of Applied Technologies.

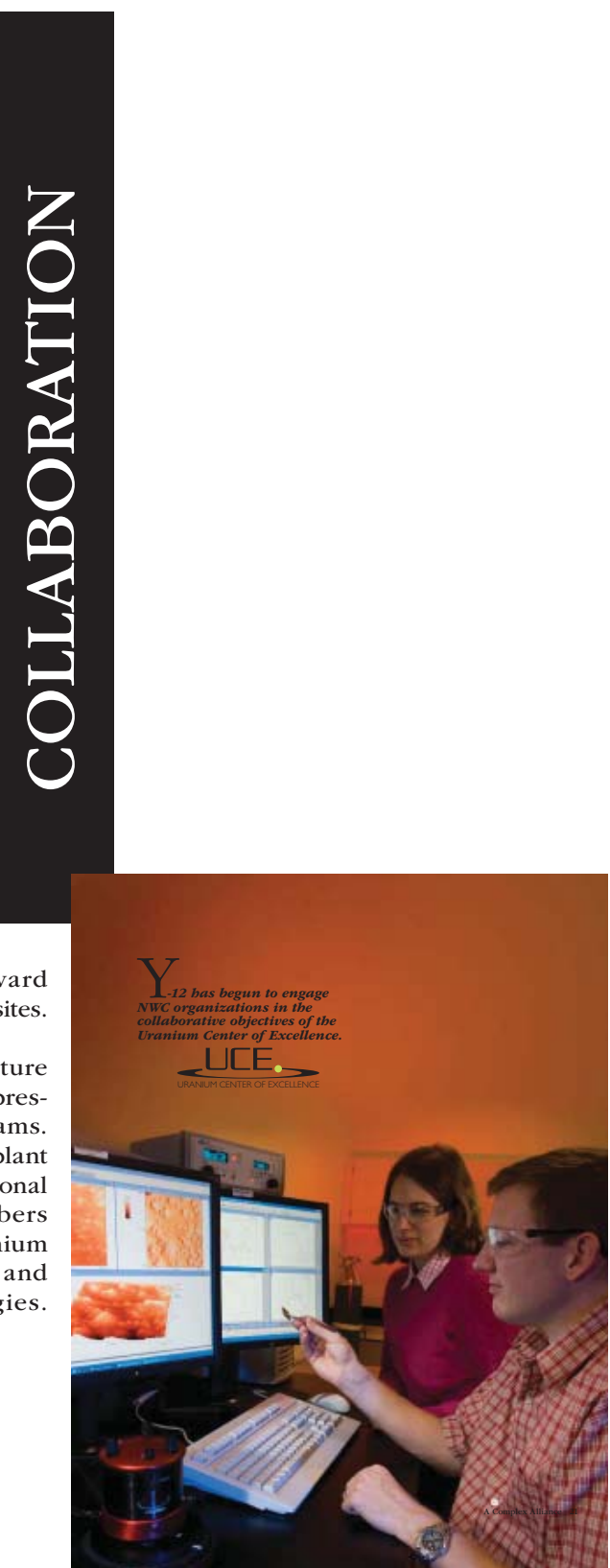

